\title{
PEMANFAATAN DAUN JATI MUDA UNTUK PEWARNAAN KAIN KAPAS PADA SUHU KAMAR
}

\section{UTILIZATION OF TEAK LEAVES FOR DYEING ON COTTON FABRIC AT ROOM TEMPERATURE}

\author{
Ainur Rosyida, Didik Achadi W \\ Prodi Kimia Tekstil, Akademi Teknologi Warga Surakarta \\ Jalan Raya Solo Baki Km.2, Kwarasan, Solo Baru - Sukoharjo \\ E-mail: kenur@atw.ac.id
}

Tanggal diterima: 11 Juli 2014, direvisi: 9 September 2014, disetujui terbit: 23 Oktober 2014

\begin{abstract}
ABSTRAK
Penelitian ini bertujuan untuk memanfaatkan ekstrak daun jati muda sebagai zat pewarna pada kain kapas dengan metode suhu kamar, sehingga mengurangi energi panas, namun menghasilkan celupan optimum. Proses pencelupan dilakukan dengan variasi $\mathrm{pH}$ dan zat fiksator tawas dan ferro sulfat. Dari hasil penelitian diketahui bahwa daun jati muda dapat digunakan untuk mewarnai kain kapas dengan arah warna bervariasi yaitu ungu, ungu kemerahan dan abu-abu. Warna yang dihasilkan tergantung dari jenis fiksator yang digunakan sedangkan ketuaan dan arah warna ditentukan oleh $\mathrm{pH}$ larutan yang digunakan dalam pencelupan. Metode pewarnaan terbukti dapat diperoleh hasil yang baik, karena diperoleh warna yang merata dan permanen. Hasil uji ketuaan warna menunjukkan bahwa pada pencelupan dengan fiksator tawas diperoleh warna ungu dengan nilai ketuaan warna yang paling tinggi pada $\mathrm{pH}$ 10, sedangkan pada pencelupan dengan ferro sulfat diperoleh warna abu-abu dengan nilai ketuaan warna paling tinggi pada $\mathrm{pH}$ 5. Ketahanan luntur warna terhadap pencucian diperoleh nilai perubahan warna yang cukup baik dengan nilai 3-4 sesuai standar Grey Scale dan untuk penodaan warna diperoleh nilai 4 sesuai standar Staining Scale. Uji ketahanan gosokan kering diperoleh nilai perubahan warna yang baik yaitu 4-5 dan pada gosokan basah dengan nilai 4 masing-masing terhadap standar Grey Scale. Hasil analisis gugus fungsi molekul zat warna daun jati muda dengan kurva FTIR (Fourier Transform Infra Red) terdapat gugus hidroksil $(-\mathrm{OH})$, gugus karbonil $(\mathrm{C}=\mathrm{O})$ dan gugus metil $(-\mathrm{CH} 3)$ yang menunjukkan adanya gugus auksokrom dan kromofor.
\end{abstract}

Kata kunci: Ekstrak daun jati, pewarnaan suhu kamar, serat kapas, zat warna alam.

\begin{abstract}
This research aimed to exploit teak leaf as textile coloration on cotton by using room temperature to reduce thermal energy yet producing optimum dyeing. The dyeing process was carried out by $\mathrm{pH}$ variation and fixator alum and ferrous sulfate. According to this research it was known that teak leaf could be used for dyeing on cotton with various shade, i.e. purple, redness purple and gray. The final color depend on the fixator whereas the color strength and shade was influenced by $\mathrm{pH}$ solution in dyeing process. These dyeing metode gave good results, since it got homogeneous and permanent color. The test results of color strength shown that the dyeing process using alum fixator got purple color with highest color strength on $p H$ 10, whereas the ferrous sulfate got gray with highest color strength on $\mathrm{pH}$ 5. The color fastness to washing showed good color change with value of 3-4 on Grey Scale Standard and staining color with value of 4 on Staining Scale Standard. The dry rubbing fastness got color change with value of 4-5, whereas on wet rubbing with value of 4 according to Grey Scale Standard. The functional group analysis of teak leaf dye with FTIR curve (Fourier Transform Infra Red) there were a hydroxyl group (-OH), carbonyl $(\mathrm{C}=\mathrm{O})$ and methyl $(-\mathrm{CH} 3)$ that shown groups of auxochrom and chromophor.
\end{abstract}

Keywords: extract, teak leaf, dyeing on room temperatur, cotton fiber, natural dyes.

\section{PENDAHULUAN}

Sebagai salah satu negara yang mempunyai kekayaan sumber daya alam yang cukup potensial, Indonesia merupakan negara yang sangat kuat dalam penyediaan bahan baku bersumber dari alam. Namun pada kenyataannya sumber daya alam yang dimiliki belum dikelola dengan maksimal kendati secara tradisional pengelolaannya telah dilakukan oleh nenek moyang kita. Tumbuhan pewarna alam merupakan salah satu sumber daya alam yang mempunyai potensi untuk digunakan sebagai zat pewarna tekstil di Indonesia, khususnya dalam pengembangan produk yang bernuansa naturalis, 
imitive, kulturis dan eksklusif serta dapat menjadi bahan baku industri tekstil yang mempunyai nilai ekonomis tinggi.

Penggunaan zat warna sintetis untuk bahan tekstil telah banyak menimbulkan masalah lingkungan karena beberapa zat warna sintetis mengandung polutan berupa logam berat yang berbahaya. Logam berat tersebut antara lain adalah $\mathrm{Cu}, \mathrm{Ni}, \mathrm{Cr}, \mathrm{Hg}$ dan Co. ${ }^{1}$ Polutan tersebut pada akhirnya akan terbuang dalam perairan umum dan mencemari lingkungan, khususnya lingkungan perairan. ${ }^{2}$ Sejak 1 Agustus 1996 negara-negara maju seperti Jerman dan Belanda telah melarang penggunaan zat pewarna berbahan kimia. Larangan ini mengacu pada CBI (Centre for the promotion of import from developing countries) Ref, CBI/NB3032 tertanggal 13 Juni 1996 tentang zat pewarna untuk bahan pakaian/clothing, alas kaki/footwear, sprei/bedlinen tidak boleh menggunakan zat warna yang mengandung bahan kimia beracun, tetapi zat warna yang tidak mempunyai efek samping terhadap lingkungan dan kesehatan. ${ }^{3}$ Sekitar 10$15 \%$ zat warna terutama zat warna azo yang dilepaskan ke lingkungan selama proses pencelupan membuat limbah berwarna yang berbahaya dan membawa sejumlah besar pewarna dan aditif lain yang ditambahkan selama proses pewarnaan. Limbah tersebut juga dapat mengalami degradasi untuk membentuk produk yang sangat beracun dan karsinogen. ${ }^{4}$

Indonesia mempunyai kekayaan yang melimpah, salah satu kekayaan tersebut adalah keanekaragaman hayati yang dapat dimanfaatkan sebagai zat warna alam dan ini sudah dilakukan sejak dulu. Namun beberapa kendala dari penggunaan zat warna alam adalah proses pewarnaannya harus diulang-ulang, variasi warna sangat terbatas dan ketersediaannya terbatas dipasaran sehingga zat warna alam dianggap kurang praktis untuk digunakan. ${ }^{5}$ Untuk itu perlu adanya penelitian lebih lanjut guna diperoleh jenis - jenis tumbuhan yang berpotensi digunakan sebagai zat warna tekstil dalam hal ini daun jati muda, untuk menambah jumlah ketersediaan dan jenis pewarna alam yang dapat digunakan sebagai zat pewarna tekstil. Selain itu untuk mendapatkan teknik/cara pewarnaan yang lebih baik, guna diperoleh hasil pewarnaan yang lebih optimal dengan waktu yang lebih singkat, sehingga penggunaan zat warna alam lebih diminati. Zat warna alam untuk bahan tesktil pada umumnya diperoleh dari hasil ekstrak berbagai bagian tumbuhan seperti akar, kayu, daun, biji ataupun bunga. Pengrajin-pengrajin batik telah banyak mengenal tumbuh-tumbuhan yang dapat mewarnai bahan tekstil beberapa diantaranya adalah : daun pohon nila (indofera), kulit pohon soga tingi (Ceriops candolleana arn), kayu tegeran (Cudraina javanensis), kunyit (Curcuma), teh (Tea), akar mengkudu (Morinda citrifelia), Kulit soga jambal
(Pelthophorum feruginum) dan kesumba (Bixa orelana). Pengolahan atau pengambilan zat warna alam dari tumbuh-tumbuhan dilakukan melalui 2 cara yaitu ekstraksi dan fermentasi.

Adanya kandungan pigmen antosianin pada daun jati, maka daun jati muda dapat dimanfaatkan sebagai pewarna alam dengan hasil pewarnaan berupa warna-warna yang lebih variatif dan menarik. Pada Gambar 1 disajikan rumus struktur antosianin dan Tabel 1 komponen yang terkandung dalam antosianin. ${ }^{6}$

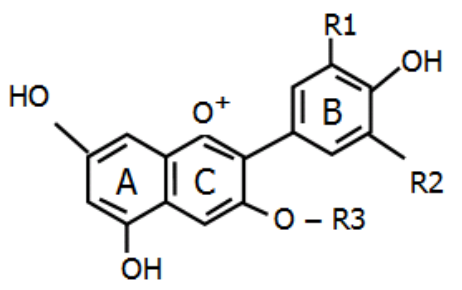

Gambar 1. Rumus struktur antosianin ${ }^{6}$

Tabel 1. Komponen dalam antosianin ${ }^{6}$

\begin{tabular}{lcc}
\hline \multicolumn{1}{c}{ Antosianin } & $\mathbf{R 1}$ & $\mathbf{R 2}$ \\
\hline Delfinidin & $\mathrm{OH}$ & $\mathrm{OH}$ \\
Peturidin & $\mathrm{OH}$ & $\mathrm{OCH}_{3}$ \\
Malvidin & $\mathrm{OCH}_{3}$ & $\mathrm{OCH}_{3}$ \\
Sianidin & $\mathrm{OH}$ & $\mathrm{H}$ \\
Peonidin & $\mathrm{OCH}_{3}$ & $\mathrm{H}$ \\
Pelargonidin & $\mathrm{H}$ & $\mathrm{H}$ \\
\hline
\end{tabular}

Dari struktur molekul antosianin tersebut dapat diketahui bahwa zat warna dari daun jati muda merupakan zat organik yang tidak jenuh dan termasuk golongan flavonoid. Struktur utamanya ditandai dengan adanya dua cincin aromatik benzene $\left(\mathrm{C}_{6} \mathrm{H}_{6}\right)$ yang dihubungkan dengan tiga atom karbon. Ketiga atom karbon tersebut dirapatkan oleh sebuah atom oksigen, sehingga terbentuk cincin diantara dua cincin benzena. ${ }^{7} \mathrm{Di}$ dalam larutan, antosianin berada dalam lima bentuk kesetimbangan tergantung pada kondisi $\mathrm{pH}$. Kelima bentuk tersebut yaitu kation flavilium, basa karbinol, kalkon, basa quinonoidal dan quinonoidal anionik. Pada $\mathrm{pH}$ sangat asam (pH 1-2) bentuk dominan antosianin adalah kation flavilium. Pada bentuk ini, antosianin berada dalam kondisi paling stabil dan paling berwarna. Ketika $\mathrm{pH}$ meningkat diatas 4 , berbentuk senyawa antosianin berwarna kuning (bentuk kalkon), senyawa berwarna biru (berbentuk quinoid), atau senyawa yang tidak berwarna (basa karbinol). ${ }^{6}$ Dengan ion logam, antosianin membentuk senyawa kompleks yang berwarna abu-abu violet. ${ }^{7}$ Oleh karena itu dalam penelitian ini dilakukan percobaan pencelupan ekstrak daun jati muda dengan variasi $\mathrm{pH}$.

Serat kapas dihasilkan dari rambut biji tanaman Gossypium. Analisa menunjukkan bahwa serat kapas tersusun atas selulosa. 
Selulosa $/\left(\mathrm{C}_{6} \mathrm{H}_{10} \mathrm{O}_{5}\right)_{\mathrm{n}}$ merupakan polimer linier yang tersusun dari kondensasi molekul glukosa $\left(\mathrm{C}_{6} \mathrm{H}_{12} \mathrm{O}_{6}\right)$. Derajat polimerisasi selulosa pada kapas kira-kira 10.000 dengan berat molekul kira-kira 1.500.000. Dinding sekunder serat terdiri dari selulosa murni dan dinding primer juga mengandung selulosa. Pada setiap molekul glukosa terdapat 3 gugus reaktif hidroksil $(\mathrm{OH})$ yang mempunyai kemampuan untuk mengikat molekul air/zat kimia. ${ }^{8}$

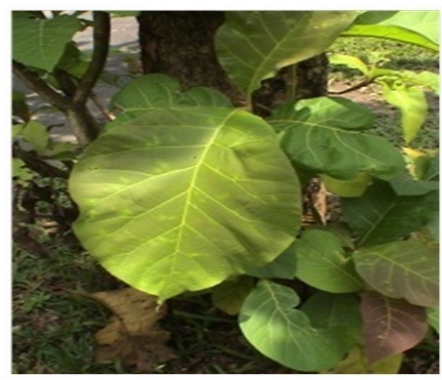

Gambar 2. Daun jati muda

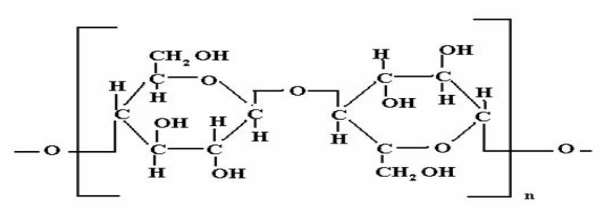

Gambar 3. Struktur molekul sellulosa

Tujuan yang ingin dicapai dalam kegiatan penelitian ini adalah memanfaatkan daun jati muda sebagai zat pewarna alam pada kain kapas dan mengetahui warna - warna yang dihasilkan pada variasi $\mathrm{pH}$ dan zat fiksator yang berbeda (tawas dan ferro sulfat). Pencelupan dilakukan dengan metode suhu kamar dengan cara yang tepat untuk mendapatkan hasil pewarnaan yang optimal, sehingga dapat mengurangi energi panas.

\section{METODE PENELITIAN}

\section{Bahan dan peralatan}

Bahan yang diperlukan meliputi : kain kapas putih siap celup, kertas $\mathrm{pH}$, daun jati muda, serta bahan kimia (grade teknis) antara lain $\mathrm{NaCl}$, pembasah/Wetting agent, $\mathrm{CH}_{3} \mathrm{COOH}$ (asam asetat), $\mathrm{Na}_{2} \mathrm{CO}_{3}, \mathrm{Al}_{2}\left(\mathrm{SO}_{4}\right)_{3} /$ Tawas, detergen/sabun, $\mathrm{FeSO}_{4} /$ Ferro Sulfat, dan lain lain.

Peralatan yang digunakan dalam percobaan antara lain mesin jigger, peralatan gelas lengkap, termometer, Kompor gas dan timbangan, sedangkan peralatan uji yang digunakan adalah Lounder $\mathrm{O}$ Meter merk Super Star Textile Machinery, Grey Scale (standar skala perubahan warna), Stanning Scale (standar skala penodaan), Crockmeter (alat uji gosokan kain), Uji gugus fungsi dengan Fourier Transform Infra Red (FTIR) merk Shimadzu dan Spektrofotometer Data Color 600.
Lokasi Penelitian dilakukan di Laboratorium Finishing, Lab. Evaluasi Kimia Tekstil Akademi Teknologi Warga Surakarta dan Lab. Finishing PT. Danliris.

\section{Percobaan}

Percobaan dilakukan sesuai tahapan proses yang disajikan pada Gambar 4, meliputi ekstraksi daun jati muda, proses pencelupan ekstrak daun jati muda pada suhu kamar, proses pencucian dan proses pengeringan.

Ekstraksi daun jati muda dengan air Perbandingan 1:6,

Perendaman 12 jam, dan perebusan 15 menit

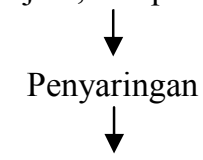

Larutan ekstrak daun jati muda, 301 (vlot 1:30)

(Warna merah keunguan, $\mathrm{pH}: 5-5,5$ )

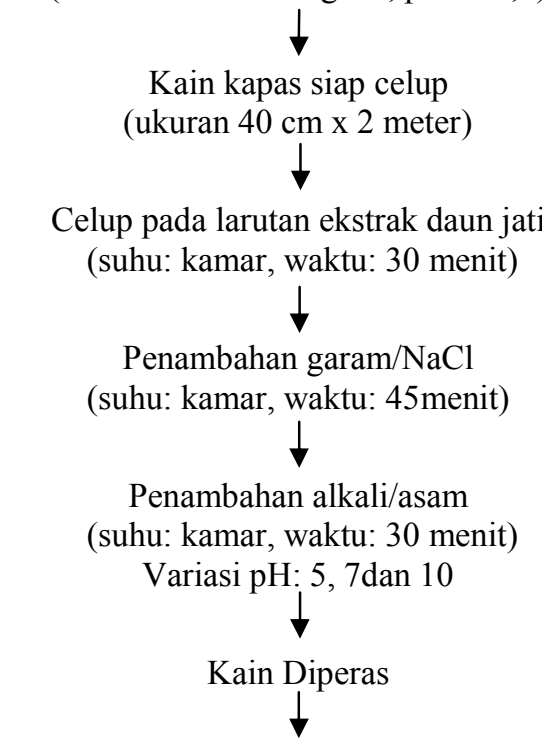

Fiksasi dengan Tawas/Ferro Sulfat, 5 g/l

(suhu: kamar, 15 menit)

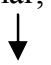

Pencucian panas, sabun, panas (suhu: $70-80^{\circ} \mathrm{C}$, waktu $10-1$ menit)

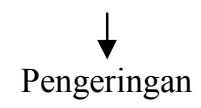

Gambar 4. Tahapan proses pewarnaan kain kapas dengan ekstrak daun jati muda

\section{Proses pewarnaan}

Proses pewarnaan dilakukan pada suhu kamar, sehingga dapat mengurangi energi panas, dengan tahapan sebagai berikut :

Kain kapas siap celup dimasukkan terlebih dahulu ke dalam mesin jigger, kemudian larutan ekstrak daun jati muda yang telah ditambah zat pembasah 
dimasukkan ke dalam mesin jigger. Kain mulai diproses pada suhu kamar selama 30 menit, setelah itu tambahkan garam $/ \mathrm{NaCl}$ (yang sudah dilarutkan terlebih dahulu) ke dalam larutan celup dan aduk hingga rata. Lanjutkan proses pencelupan selama 45 menit pada suhu kamar.

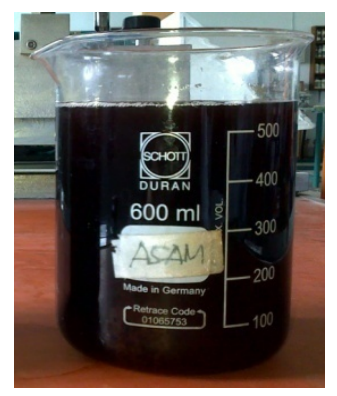

Gambar 5. Ekstrak daun jati muda

Berikutnya tambahkan asam/alkali pada larutan celup sesuai dengan variasi $\mathrm{pH}(5,7$ dan 10), lanjutkan proses pencelupan pada suhu kamar selama 30 menit. Kain yang telah diwarnai selanjutnya diperas dan di fiksasi dengan tawas/ferro sulfat selama 15 menit pada temperatur kamar. Selesai fiksasi kain dilakukan pencucian, meliputi pencucian panas, sabun dan bilas, setelah itu kain dikeringkan.Pada percobaan pencelupan kain kapas, digunakan resep sebagai berikut :

\section{Resep :}

- Larutan ekstrak pewarna alam

- Teepol : $1 \mathrm{cc} / 1$

- $\mathrm{NaCl} \quad: 5 \mathrm{~g} / 1$

- Fiksator $\quad: 5 \mathrm{~g} / 1 \mathrm{FeSO}_{4} / \mathrm{Al}_{2}\left(\mathrm{SO}_{3}\right)_{4}$

- $\mathrm{Na}_{2} \mathrm{CO}_{3}$

- $\mathrm{CH}_{3} \mathrm{COOH}$

- Suhu

- Waktu

- Vlot

: $\mathrm{x}$ g/l atau

: $\mathrm{x} \mathrm{cc/1}$

: Kamar

: 2 jam

$: 1: 30$

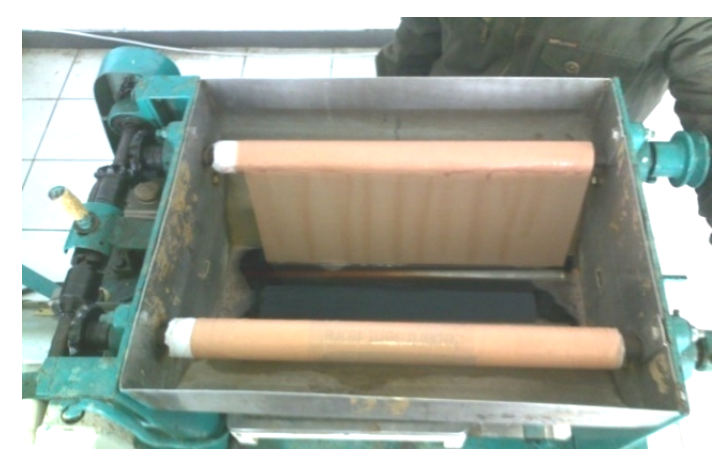

Gambar 6. Proses pewarnaan pada mesin jigger

\section{Pengujian}

Pengujian yang dilakukan pada kain hasil pencelupan adalah pengujian Ketahanan Luntur Warna terhadap Pencucian (SNI. 080285-98), Ketahanan Luntur Warna Terhadap Gosokan (SNI. 080288-89) dan Pengujian Ketuaan Warna. Sedangkan analisis gugus fungsi dari zat warna daun jati muda dilakukan dengan Fourier Transform Infra Red (FTIR).

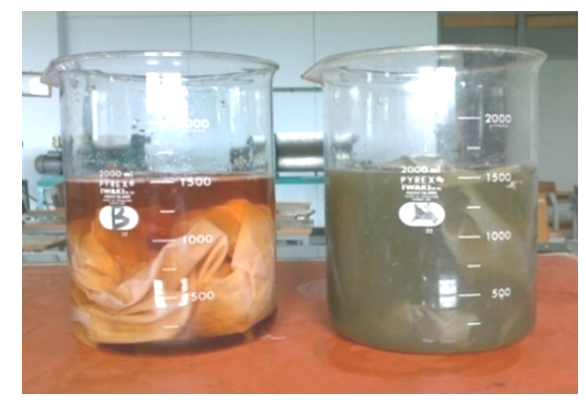

Gambar 7. Fiksasi dengan tawas dan ferro sulfat

\section{HASIL DAN PEMBAHASAN}

\section{Hasil ekstraksi daun jati}

Larutan hasil ekstrak daun jati muda berwarna ungu kemerahan dengan tingkat keasaman berkisar antara pH: 5-5,5. Antosianin yang terkandung dalam daun jati muda bersifat larut dalam air sehingga dapat memberikan warna merah kecoklatan pada larutan ekstrak daun jati. ${ }^{9}$ Pigmen antosianin terdapat dalam cairan sel tumbuhan, senyawa ini berbentuk glukosida dan menjadi penyebab warna merah kecoklatan. ${ }^{10}$ Pada saat mengekstrak daun jati muda dilakukan pada temperatur kamar selama 12 jam dan dilakukan pemanasan sampai suhu mendidih dalam waktu yang singkat (15 menit) agar tidak banyak terjadi degradasi dan kerusakan pada antosianin selama proses ekstraksi. Temperatur dapat menyebabkan antosianin menuju bentuk yang tidak berwarna, yaitu basa karbinol dan kalkon. Kerusakan akibat pemanasan ini dapat terjadi melalui dua tahap. Pertama hidrolisis terjadi pada ikatan glikosidik antosianin, sehingga menghasilkan aglikon-aglikon yang tidak stabil. Kedua, cincin aglikon terbuka membentuk gugus karbinol dan kalkon. Degradasi ini dapat terjadi lebih lanjut jika terdapat oksidator, sehingga terbentuk senyawa yang berwarna coklat. ${ }^{3}$

Hasil analisa kurva FTIR pada bubuk zat warna dari daun jati muda disajikan pada Gambar 8, menunjukkan bahwa pita lebar kuat dekat bilangan gelombang $3400 \mathrm{~cm}^{-1}$ menunjukkan adanya gugus hidroksil (-OH) yang merupakan gugus auksokrom, yaitu gugus yang mengikat antara zat warna dengan serat sehingga zat warna/pigmen dalam daun jati mudadapat berikatan 


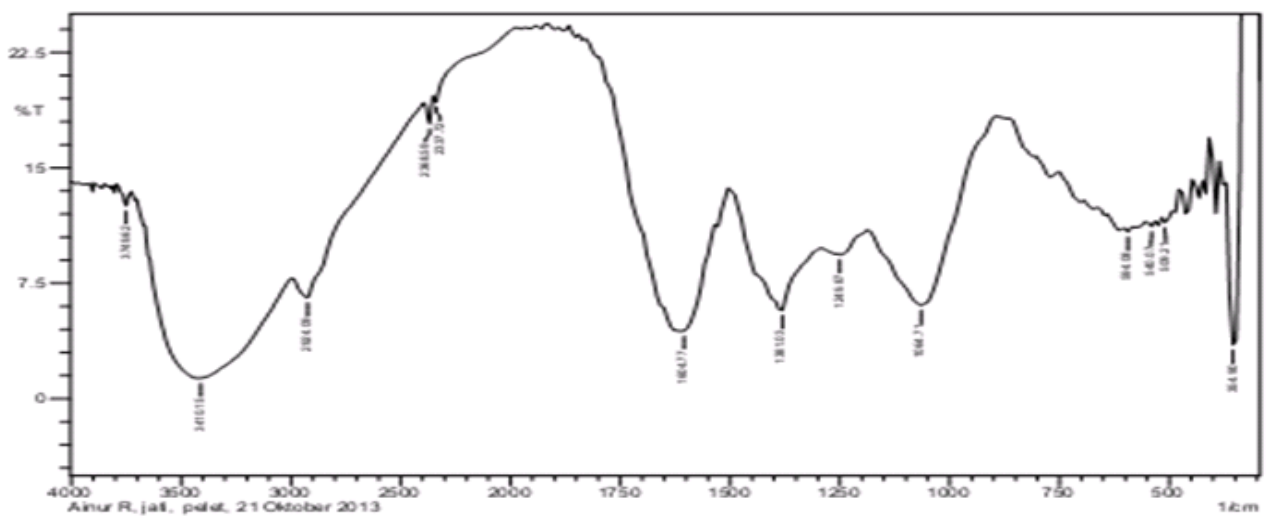

Gambar 8. Hasil uji FTIR pada serbuk zat warna daun jati muda

dengan serat kapas, pita kuat dekat $1600 \mathrm{~cm}^{-1}$, timbul dari gugus karbonil $(\mathrm{C}=\mathrm{O})$ yang merupakan gugus kromofor (gugus pembawa warna) dari pigmen pada daun jati, selain itu pita tajam pada $1380 \mathrm{~cm}^{-1}$ diperkirakan adanya gugus metil (-CH3). ${ }^{11}$

\section{Hasil pencelupan}

Dari hasil percobaan dapat diketahui bahwa daun jati muda dapat mewarnai serat kapas dengan warna ungu, ungu kemerahan dan coklat, karena daun jati muda mengandung antosianin. Antosianin dapat mewarnai bahan kapas secara permanen karena kain yang telah dicelup tidak luntur warnanya setelah dilakukan beberapa kali pencucian, sehingga dapat memenuhi persyaratan untuk digunakan sebagai zat warna tekstil.

Selama proses pewarnaan, serat kapas direndam pada larutan ekstrak daun jati. Saat perendaman dalam air/larutan pencelupan, serat kapas akan menggelembung/swelling karena menyusupnya/adanya molekul-molekul air dan zat warna alam yang masuk kedalam serat. Pori serat akan terbuka dan antosianin selaku pigmen pewarna alam yang terdapat dalam larutan celup dapat masuk ke dalam serat bersama-sama larutan pencelupan. Antosianin yang telah masuk/teradsorbsi ke permukaan serat akan terabsorbsi dan mengendap di dalam serat. Pengendapan antosianin ini akan bertambah banyak saat kain yang telah diwarnai/dicelup dilakukan fiksasi, sehingga garam-garam logam (tawas dan ferro sulfat) yang masuk ke dalam serat dapat mengendapkan antosianin dalam jumlah yang lebih banyak dibanding kain hasil pencelupan yang dilakukan tanpa fiksasi. Hal ini dapat terlihat pada kain yang difiksasi warnanya terlihat lebih tua dan tidak mudah luntur saat dilakukan pencucian.

Pada pewarnaan kain kapas tanpa menggunakan zat fiksator, akan diperoleh warna ungu muda Pada hasil pewarnaan menunjukkan bahwa kain kapas yang telah diwarnai dengan larutan ekstrak daun jati mudadiperoleh hasil pewarnaan yang merata dan tidak mudah luntur kembali. Ini disebabkan dalam pewarnaan digunakan metode/cara yang disesuaikan dengan sifat fisik dan kimia dari serat kapas.

Proses pewarnaan dilakukan tanpa proses mordanting tetapi langsung dimulai dengan pencelupan kain kapas dalam larutan pewarna alam pada suhu kamar selama 30 menit. Pada tahap ini partikel zat warna mulai bergerak dari larutan pewarnaan menuju permukaan serat sehingga terjadi penyerapan/adsorbsi pada permukaan serat kapas menuju kedalam serat. Selanjutnya partikel zat warna akan terserap pada bagian yang lebih dalam/terabsorbsi pada serat menuju inti serat. Proses penyerapan zat warna pada serat menjadi bertambah bila pada larutan celup ditambahkan garam dapur $/ \mathrm{NaCl}$. Ini karena dalam larutan, sellulosa/serat kapas akan lebih banyak muatan negatifnya maka untuk mengurangi muatan negatif pada serat ditambahkan elektrolit/ $\mathrm{NaCl}$.

Banyaknya partikel zat warna yang terserap pada serat akan mempengaruhi banyaknya partikel zat warna yang dapat berikatan dengan serat saat dilakukan fiksasi. Oleh sebab itu fiksasi dilakukan setelah partikel zat warna telah terserap secara maksimal ke dalam serat agar partikel zat warna yang berikatan dengan serat jumlahnya lebih banyak, sehingga akan diperoleh hasil pewarnaaan yang lebih tua/optimal dengan satu kali proses pewarnaan saja (tidak perlu diulang - ulang).

Proses pewarnaan juga diperoleh hasil yang merata karena pada larutan pewarnaan ditambahkan zat aktif permukaan (Teepol), walaupun ditambahkan dalam jumlah yang kecil tetapi dapat mengurangi tegangan antar muka pada larutan pewarnaan dan bahan tekstil/kain kapas, sehingga dapat mempercepat kontak dan penyerapan larutan pewarna ke dalam serat. Selain itu penambahan zat aktif permukaan ini dapat menambah kerataan 
penyerapan antosianin pada serat, sehingga penyerapan partikel zat warna akan terjadi secara merata pada seluruh permukaan kain.

\section{Hasil fiksasi, arah warna dan ketuaan warna}

Hasil uji ketuaan warna dan arah warna celupan daun jati muda ditunjukkan dari data uji Spektrofotometer seperti disajikan pada Tabel 2. Nilai DL yaitu lightenes menunjukkan tua dan muda warna dibanding dengan nilai standar yang digunakan. Nilai DL positif menunjukkan bahwa kain yang diuji lebih muda dari kain standar, sedangkan bila nilainya negatif menunjukkan bahwa kain yang diuji lebih tua dari kain standar. Standar yang digunakan dalam uji ini adalah kain kapas putih yang belum dicelup. Hasil uji spektofotometri juga dapat menunjukkan arah warna celupan yang secara keseluruhan hasil celupan dengan daun jati muda cenderung menghasilkan arah warna kemerahan $(\mathrm{Da}+)$. Pada kain celupan yang tanpa fiksasi dan yang di fiksasi dengan tawas, semakin besar nilai Da pada kain yang diuji menunjukkan kain mempunyai warna merah tua hingga ungu tua. Sedangkan untuk nilai Db menunjukkan nilai positif yang memberikan hasil celupan mengarah pada warna kekuningan.

Pada kain yang difiksasi dengan tawas/ $\mathrm{Al}_{2}\left(\mathrm{SO}_{3}\right)_{4}$, semakin kecil nilai $\mathrm{Db}+$ terlihat warna ungu yang semakin tua, sedangkan semakin besar nilai $\mathrm{Db}+$ diperoleh warna ungu yang lebih muda. Hal-hal tersebut sesuai dengan warna hasil celupan secara visual yaitu diperoleh warna-warna ungu sampai ungu kemerahan. Pengaruh $\mathrm{pH}$ akan mempengaruhi ketuaan warna, ini dapat terlihat pada sampel kain yang dicelup dengan $\mathrm{pH} 10(\mathrm{Da}=$ $+6,15$ dan $\mathrm{Db}=+2,78)$ diperoleh kain warna ungu dengan nilai ketuaan yang lebih tinggi dibanding hasil pewarnaan pada $\mathrm{pH} 7(\mathrm{Da}=+4,86$ dan $\mathrm{Db}=$ $+5,25)$ dan pada $\mathrm{pH} 5(\mathrm{Da}=+4,59$ dan $\mathrm{Db}=+4,99)$ diperoleh warna ungu kemerahan. Proses fiksasi dengan tawas tidak akan merubah arah warna pada hasil celupan karena tawas $/ \mathrm{Al}_{2}\left(\mathrm{SO}_{3}\right)_{4}$ merupakan senyawa kimia yang tidak berwarna sehingga hasilnya hanya akan menguatkan warna. Dengan $\mathrm{pH}$ yang semakin tinggi akan memberikan kekuatan warna yang semakin tinggi. Hal ini sesuai dengan nilai DL, semakin meningkat $\mathrm{pH}$ pada penggunaan tawas, maka ketuaan warna semakin meningkat atau nilai DL semakin besar. Pencelupan tanpa fiksator diperoleh warna muda, karena antosianin yang telah masuk kedalam serat setelah pencelupan sebagian besar dapat keluar lagi dari serat saat pencucian. Hal ini disebabkan karena tidak ada zat fiksator yang dapat mengikat antosianin dalam serat dengan kuat, sehingga pigmen dari daun jati muda tersebut mudah terlepas dan dapat keluar lagi dari serat saat pencucian dilakukan.
Pencelupan dengan fiksator ferro sulfat, kain dengan nilai $\mathrm{Da}+$ dan $\mathrm{Db}+$ yang lebih besar akan diperoleh warna abu-abu. Pada kain yang dicelup dengan $\mathrm{pH}$ alkali (10) diperoleh kain dengan warna abu-abu dengan nilai ketuaan yang paling rendah (paling muda), pada $\mathrm{pH}$ netral (7) diperoleh warna abu-abu dan pada $\mathrm{pH}$ asam (5) diperoleh warna abu-abu yang lebih tua dengan nilai ketuaan warna yang paling tinggi. Hal ini sesuai dengan hasil uji ketuaan warna (DL), semakin meningkat $\mathrm{pH}$ pada penggunaan fero sulfat ketuaan warna semakin menurun atau nilai DL semakin kecil.

Tabel 2. Hasil uji arah warna dan ketuaan warna kain celupan dengan $\mathrm{Zw}$. daun jati muda

\begin{tabular}{|c|c|c|c|c|}
\hline \multirow{2}{*}{ pH } & \multirow{2}{*}{$\begin{array}{c}\text { Zat } \\
\text { Fiksator }\end{array}$} & \multicolumn{3}{|c|}{ Hasil Uji } \\
\hline & & Da* & Db* & DL* \\
\hline 5 & \multirow{3}{*}{$\begin{array}{c}\text { Tanpa } \\
\text { Fiksasi }\end{array}$} & $+4,08$ & $+1,50$ & $-12,13$ \\
\hline 7 & & $+3,70$ & $+1,89$ & $-12,16$ \\
\hline 10 & & $+3,64$ & $+2,06$ & $-12,85$ \\
\hline 5 & \multirow{3}{*}{ Tawas } & $+4,59$ & $+4,99$ & $-16,20$ \\
\hline 7 & & $+4,86$ & $+5,25$ & $-16,99$ \\
\hline 10 & & $+6,15$ & $+2,78$ & $-17,18$ \\
\hline 5 & \multirow{3}{*}{$\begin{array}{l}\text { Ferro } \\
\text { Sulfat }\end{array}$} & $+1,89$ & $+8,70$ & $-24,02$ \\
\hline 7 & & $+1,85$ & $+8,49$ & $-23,67$ \\
\hline 10 & & $+1,79$ & $+7,22$ & $-22,22$ \\
\hline
\end{tabular}

Keterangan :

$\mathrm{Da}+\quad$ : Menunjukkan arah warna merah

$\mathrm{Db}+\quad$ : Menunjukkan arah warna kuning

Da- : Menunjukkan arah warna hijau

Db- : Menunjukkan arah warna biru

DL+ : Menunjukkan sampel lebih muda dari standar

DL- : Menunjukkan sampel lebih tua dari standar

Standar : kain kapas putih (belum dicelup)

Hasil keseluruhan menunjukkan bahwa kain yang dicelup dengan ekstrak daun jati muda dan fiksasinya menggunakan zat fiksator yang berbeda dengan $\mathrm{pH}$ yang sama akan diperoleh warna yang berbeda. Sedangkan kain yang dicelup dengan menggunakan zat fiksator yang sama tetapi dengan $\mathrm{pH}$ yang berbeda akan diperoleh warna yang sama tetapi dengan nilai ketuaan warna atau arah warna yang berbeda.

\section{Ketahanan luntur warna}

Warna pada kain hasil pewarnaan juga bersifat permanen. Hal ini dapat dilihat dari nilai hasil pengujian ketahanan luntur warna pada kain yang telah dicelup ekstrak daun jati muda dengan berbagai variasi $\mathrm{pH}$ dan fiksator diperoleh nilai Grey Scale/perubahan warna umumnya hampir sama. Pada kain yang difiksasi dengan tawas dengan $\mathrm{pH}$ yang berbeda $(5,7$ dan 10$)$ diperoleh nilai 3-4 (cukup baik), pada kain yang difiksasi dengan ferro sulfat dan $\mathrm{pH}$ yang berbeda diperoleh 
nilai 3-4 (cukup baik). Sedangkan pada kain yang pencelupannya tanpa fiksasi diperoleh nilai perubahan warna 3 (cukup). Untuk Staining Scale/penodaan warna diperoleh pada kain yang tanpa difiksasi maupun yang difiksasi dengan tawas, ferro sulfat dengan variasi $\mathrm{pH}$ larutan celup diperoleh nilai 4 (baik), artinya kain hasil celupan mempunyai nilai tahan luntur terhadap penodaan yang baik.

Nilai perubahan warna yang cukup baik pada hasil uji ketahanan luntur warna terhadap pencucian ini disebabkan pigmen pada daun jati muda (antosianin) yang terkandung dalam larutan pewarna alam selama proses pewarnaan berlangsung dapat masuk kedalam serat, berikatan, membentuk senyawa kompleks dan mengendap dalam serat kapas (selulosa). Walaupun ikatan yang terbentuk hanya merupakan ikatan hidrogen, tetapi zat fiksator (tawas dan ferro sulfat) dapat mengunci dan mengendapkan antosianin dalam serat, sehingga tidak mudah keluar dari serat. Hal ini akan menyebabkan antosianin tidak mudah lepas/keluar dari serat dan melunturi kain uji saat dilakukan uji ketahanan luntur warna terhadap pencucian, sehingga diperoleh nilai ketahanan luntur yang baik terhadap pencucian. Sedangkan pada kain yang dicelup tanpa fiksasi diperoleh nilai perubahan warna yang lebih rendah, yaitu: 3 (cukup), hal ini dikarenakan tidak ada zat fiksator yang dapat mengunci dan mengendapkan antosianin dalam serat, sehingga saat dilakukan pencucian ada sebagian antosianin yang lepas/keluar lagi dari serat karena ikatan antara serat dengan antosianin yang tidak begitu kuat (hanya ikatan hidrogen saja) dan sedikit melunturi kain uji.

Untuk penodaan warna, semua kain hasil pencelupan diperoleh nilai 4 , artinya kain hasil celupan mempunyai nilai penodaan yang baik. Hal ini disebabkan selain pigmen daun jati muda telah berikatan dengan serat dengan baik, juga karena telah sempurnanya proses pencucian/ penyabunan setelah proses pencelupan dilakukan. Sisa-sisa zat warna yang hanya menempel pada permukaan serat telah terlepas pada proses pencucian sebelumnya, sehingga pada saat dilakukan uji ketahanan luntur warna terhadap pencucian sudah tidak ada lagi antosianin yang keluar dari serat dan melunturi kain uji. Pada Tabel 4 dan 5, dapat dilihat hasil uji ketahanan luntur warna terhadap pencucian dan gosokan.

Hasil pengujian ketahanan luntur warna terhadap gosokan pada kain yang telah dicelup ekstrak daun jati muda dengan fiksator tawas dan variasi $\mathrm{pH}(5,7$ dan 10$)$ diperoleh nilai

Penodaan warna: 4 (baik), sedangkan pada kain yang tidak difiksasi dan yang difiksasi denga ferro sulfat akan diperoleh nilai penodaan warna: 4-5 (baik) . Ini artinya kain hasil pencelupan dengan daun jati muda mempunyai ketahanan gosok kering yang baik, sedangkan untuk ketahanan gosok basah pada semua kain hasil celupan dengan atau tanpa fiksasi pada semua variasi $\mathrm{pH}$ diperoleh nilai penodaan warna: 4 (baik), ini artinya kain hasil celupan mempunyai nilai ketahanan gosokan basah dan kering yang baik. Diperolehnya nilai ketahanan gosok yang baik pada kain hasil celupan disebabkan pigmen pada daun jati muda(antosianin) yang telah masuk kedalam serat telah berikatan dan mengendap di dalam serat kapas (sellulosa) sehingga sulit untuk lepas atau keluar lagi dari serat, walaupun dilakukan gosokan secara mekanik pada permukaan kain/serat. Hal inilah yang menyebabkan kain hasil pewarnaan tidak melunturi kain uji saat dilakukan uji ketahanan luntur warna terhadap gosokan.

Tabel 4. Hasil uji ketahanan luntur warna terhadap pencucian

\begin{tabular}{|c|c|c|c|c|c|c|}
\hline \multirow{3}{*}{ Sampel Uji } & \multicolumn{2}{|c|}{ Variasi Pewarnaan } & \multicolumn{4}{|c|}{ Ketahanan Luntur Warna Terhadap Pencucian } \\
\hline & \multirow{2}{*}{ pH } & \multirow{2}{*}{ Fiksator } & \multicolumn{2}{|c|}{ Perubahan Warna } & \multicolumn{2}{|c|}{ Penodaan Warna } \\
\hline & & & GS & $\mathrm{CD}$ & SS & $\mathrm{CD}$ \\
\hline 1. & \multirow{3}{*}{$\begin{array}{c}\text { Asam } \\
(\mathrm{pH}: 5)\end{array}$} & Tanpa Fiksator & 2 & 5,75 & $3-4$ & 4,8 \\
\hline 2. & & Tawas & $3-4$ & 2,5 & 4 & 4 \\
\hline 3. & & Ferro Sulfat & 3 & 3 & 4 & 4 \\
\hline 4. & \multirow{3}{*}{$\begin{array}{l}\text { Netral } \\
(\mathrm{pH}: 7)\end{array}$} & Tanpa Fiksator & $3-4$ & 2,5 & 4 & 4 \\
\hline 5. & & Tawas & $3-4$ & 2,5 & 4 & 4 \\
\hline 6. & & Ferro Sulfat & $3-4$ & 2,5 & 4 & 4 \\
\hline 7. & \multirow{3}{*}{$\begin{array}{c}\text { Alkali } \\
(\mathrm{pH}: 10)\end{array}$} & Tanpa Fiksator & $3-4$ & 2,5 & $3-4$ & 4,8 \\
\hline 8. & & Tawas & $3-4$ & 2,1 & 4 & 4 \\
\hline 9. & & Ferro Sulfat & $3-4$ & 2,1 & 4 & 3 \\
\hline
\end{tabular}


Tabel 5. Hasil uji ketahanan luntur warna terhadap gosokan

\begin{tabular}{|c|c|c|c|c|c|c|}
\hline \multirow{3}{*}{$\begin{array}{c}\text { Sampel } \\
\text { Uji }\end{array}$} & \multicolumn{2}{|c|}{ Variasi Pewarnaan } & \multicolumn{4}{|c|}{ Ketahanan Luntur Warna Terhadap Gosokan } \\
\hline & \multirow{2}{*}{$\mathbf{p H}$} & \multirow{2}{*}{ Fiksator } & \multicolumn{2}{|c|}{ Kering } & \multicolumn{2}{|c|}{ Basah } \\
\hline & & & SS & CD & SS & CD \\
\hline 1. & \multirow{3}{*}{$\begin{array}{c}\text { Asam } \\
(\mathrm{pH}: 5)\end{array}$} & Tanpa Fiksator & $4-5$ & 2 & 4 & 3 \\
\hline 2. & & Tawas & $4-5$ & 2 & 4 & 4 \\
\hline 3. & & Ferro Sulfat & $4-5$ & 1 & 4 & 3 \\
\hline 4. & \multirow{3}{*}{$\begin{array}{l}\text { Netral } \\
(\mathrm{pH}: 7)\end{array}$} & Tanpa Fiksator & $4-5$ & 2 & $3-4$ & 4,8 \\
\hline 5. & & Tawas & 4 & 3 & 4 & 4 \\
\hline 6. & & Ferro Sulfat & $4-5$ & 2 & $3-4$ & 4,8 \\
\hline 7. & \multirow{3}{*}{$\begin{array}{c}\text { Alkali } \\
(\mathrm{pH}: 10)\end{array}$} & Tanpa Fiksator & $4-5$ & 2 & 4 & 4 \\
\hline 8. & & Tawas & 4 & 4 & 4 & 4 \\
\hline 9. & & Ferro Sulfat & $4-5$ & 2 & 4 & 3 \\
\hline
\end{tabular}

GS : Grey Scale/Skala Penodaan

CD : Colour Difference

SS : Staining Scale/Skala Perubahan

\section{KESIMPULAN}

Daun jati muda dapat dimanfaatkan sebagai pewarna tekstil karena dapat mewarnai kain kapas secara merata dan permanen. Metode yang dilakukan dengan cara perendaman kain dalam larutan ekstrak daun jati muda pada suhu kamar, sehingga dapat mengurangi energi panas, namun diperoleh hasil pewarnaan yang baik, karena menghasilkan ketuaan warna yang cukup baik, merata dan memiliki ketahanan luntur warna dengan nilai yang cukup baik hingga baik (3-4 hingga 4-5) seperti ditunjukkan dari hasil uji tahan luntur warna terhadap pencucian dan gosokan.

Hasil uji Spektrofotometri dengan nilai Da, $\mathrm{Db}$ dan DL menunjukkan ketuaan warna dan arah warna. Penggunaan jenis fiksator yang berbeda akan menghasilkan pewarnaan yang berbeda, dengan tawas akan diperoleh warna ungu sampai ungu kemerahan, sedangkan dengan ferro sulfat akan diperoleh warna abu-abu sampai abu-abu kemerahan. Pada kain yang difiksasi dengan tawas / $\mathrm{Al}_{2}\left(\mathrm{SO}_{3}\right)_{4}$, semakin kecil nilai $\mathrm{Db}+$ terlihat warna ungu yang semakin tua, sedangkan semakin besar nilai $\mathrm{Db}+$ diperoleh warna ungu yang lebih muda. $\mathrm{pH}$ larutan celup akan mempengaruhi ketuaan warna, dengan $\mathrm{pH} 10$ diperoleh kain warna ungu dengan nilai ketuaan yang lebih tinggi dibanding hasil pewarnaan pada $\mathrm{pH} 7$ dan pada $\mathrm{pH} 5$ diperoleh warna ungu kemerahan.

Pencelupan dengan fiksator ferro sulfat, pada pH 10 diperoleh kain dengan warna abu-abu dengan nilai ketuaan yang paling rendah (paling muda), pada $\mathrm{pH} 7$ diperoleh warna abu-abu dan pada $\mathrm{pH} 5$ diperoleh warna abu-abu yang lebih tua dengan nilai ketuaan warna yang paling tinggi. Semakin meningkat $\mathrm{pH}$ ketuaan warna semakin menurun atau nilai DL semakin kecil. Fiksasi dengan tawas dan fero sulfat dapat meningkatkan ketahanan luntur pada kain hasil celupan dan penggunaan $\mathrm{pH}$ yang berbeda pada pencelupan berpengaruh pada fiksasi zat warna dan mempengaruhi arah warna serta ketuaannya, sehingga dapat memberikan variasi arah warna.

Hasil analisis gugus fungsi molekul zat warna daun jati muda terdapat gugus hidroksil $(-\mathrm{OH})$, gugus karbonil $(\mathrm{C}=\mathrm{O})$ dan gugus metil (-CH3) yang menunjukkan adanya gugus auksokrom dan kromofor.

\section{PUSTAKA}

${ }^{1}$ Sugiyana, D, (2003), Pencemaran Logam Berat pada Limbah Industri Tekstil dan Alternatif Material Penyerap Ekonomis. Jurnal Arena Tekstil, No. 39.

${ }^{2}$ Wagner, S., (2003), Improvement in Product and Processing to Diminish Enviromental Impact, COTTECH Conference Raleigh, November, hal.11-12.

${ }^{3}$ Kwartiningsih, E., (2009), Zat Warna Alami Tekstil,. Ekuilibrium, Vol 8. No.1, hal 41-47, UNS, Surakarta.

${ }^{4}$ Ratna, Padhi. B.S, (2012), Pollution Due To Synthetic Dyes Toxicity \& Carcinogenicity Studies And Remediation, International Journal Of Environmental Sciences, Volume 3, No. 3

${ }^{5}$ Ditjen UKM, Tingkatkan Nilai Batik Dengan Zat Warna Alam. http: //ikm. kemenperin.go.id/ Publikasi/ Kumpulan Artikel.

${ }^{6}$ Sea Fast Center, 2013, Merah Ungu Antosianin". Ebook IPB, Ebookdig.biz/ebook/q/pdf/ antosianin/ html

${ }^{7}$ Koswara, S, (2009), Pewarna Alami : Produksi Pangan dan Penggunaannya. eBook Pangan.com. 
${ }^{8}$ Hollen.N, Textiles, (1984), I. Mac Millan Publishing Co., Inc, New York,.hal 36.

${ }^{9}$ Rosyida, A, (2013), Pembuatan Zat Warna Tekstil dari Tumbuhan (Pewarna Alam) dan Teknik Pewarnaannya pada Bahan Tekstil Untuk Mendapatkan Hasil yang Optimal, Laporan Penelitian HB, AT.Warga.
${ }^{10}$ Kembaren, Riahna, dkk. (2013), Ekstraksi dan Karakterisasi Serbuk Nano Pigmen dari Daun Tanaman Jati muda(Tectona grandis linn. F), Prosiding Semirata FMIPA, Universitas Lampung,

${ }^{11}$ Sastrohamidjojo, H, (2006), Spektroskopi, Liberty, Jogjakarta, Cetakan ke 3 
Arena Tekstil Vol. 29 No. 2, Desember 2014: 115-124 